\title{
Effects of Acceptance and Commitment Training Plus Behavior Parent Training on Parental Implementation of Autism Treatment
}

\author{
Meredith L. Andrews ${ }^{1}$ [ $\cdot$ Yors A. Garcia ${ }^{2} \cdot$ Robyn M. Catagnus $^{1} \cdot$ Evelyn R. Gould $^{3}$
}

Accepted: 2 November 2021 / Published online: 29 November 2021

(c) Association for Behavior Analysis International 2021

\begin{abstract}
The objective of this study was to examine the effects of acceptance and commitment training (ACT) plus behavior parent training (BPT), when delivered via telehealth, on parental implementation of behavioral strategies, experiential avoidance (EA), and stress. The study also examined the subsequent effects on the parents' autistic children's behaviors. A multiple baseline design was implemented across four parent-child dyads who participated in the online training. The findings showed that ACT+BPT resulted in parental implementation reaching and maintaining high levels. The training also decreased EA and stress in three parents. Moreover, the parents' ratings of their children's challenging behaviors decreased. However, such a trend was not as clearly depicted by direct measures of the children's behaviors. A social validity interview revealed parents found ACT beneficial in assisting them to learn and use the BPT strategies. Implications and suggestions for future research are discussed.
\end{abstract}

Keywords Behavior parent training $\cdot$ Acceptance and commitment training $\cdot$ Autism $\cdot$ Telehealth $\cdot$ Adherence

The manifestation of challenging behaviors in autistic children often negatively affects the children and their families (see Botha et al., 2021, for a discussion on the use of identity-first language over person-first language used throughout this article). Challenging behaviors such as tantrums, aggression, and self-injurious behavior can restrict children's sociability even more so than deficits in communication (Argumedes et al., 2018; Matson et al., 2013). Such behaviors can also hinder effective training and education, and without support or intervention, often continue throughout adulthood (Matson \& Rivet, 2008). The presence of challenging behaviors has also been shown to increase parental stress (Bonis, 2016; McStay et al., 2014; Zaidman-Zait et al., 2014), decrease the quality of sibling relationships (Jones et al., 2019), and lead to overall poor family functioning (Sikora et al., 2013). Given the multitude of unfavorable

Meredith L. Andrews

mandrews2@thechicagoschool.edu

1 Applied Behavior Analysis Online Program, The Chicago School of Professional Psychology, 325 North Wells Street, Chicago, IL, USA

2 Pontificia Universidad Javeriana, Bogotá, Colombia

3 McLean Hospital/ Harvard Medical School, Belmont, MA, USA outcomes, it is a primary area of concern to find effective interventions to address challenging behaviors for autistic children.

Behavior parent training (BPT) is an evidence-based treatment that involves educating and training parents to manage and intervene in their children's behaviors in settings other than the clinical environment (Bearss, Burrell, et al., 2015a). BPTs often consist of various behavior management strategies such as antecedent manipulation, reinforcement, and consequence strategies targeting the reduction of challenging behaviors. Moreover, BPTs typically involve practice opportunities either in role-plays or sessions with the parents' children (Postorino et al., 2017). BPTs can be used to teach parents behavioral skills either in-person or remotely via telehealth (e.g., Tomlinson et al., 2018; Tsami et al., 2019; Unholz-Bowden et al., 2020; Wainer \& Ingersoll, 2014). Although BPTs have demonstrated positive outcomes in core symptoms and challenging behaviors for autistic children, the majority of BPTs were not originally developed to support autistic individuals (Bearss, Johnson, et al., 2015b; Edwards et al., 2019). The Research Units in Behavioral Intervention (RUBI) Autism Network recently developed a parent-mediated manualized intervention to support autistic individuals. The RUBI program is based on applied behavior analysis (ABA) principles and consists of 
11 core sessions such as reinforcement, planned ignoring, compliance training, and functional communication training. Several empirical studies have evaluated the effectiveness of the RUBI program for parents of preschool and school-aged autistic children (Bearss et al., 2013) as well as the feasibility and efficacy in improving their children's target behaviors (Burrell et al., 2020; Fodstad et al., 2018). Studies have also demonstrated the effectiveness of delivering the intervention in group format (Edwards et al., 2019) and online (Bearss, Burrell, et al., 2018a).

Overall, RUBI studies have shown positive results for parents via active engagement in treatment sessions and high levels of attendance. However, measures of treatment adherence have been assessed by parents' demonstration of learning objectives rather than direct measures of parents' use of behavioral strategies used with their children (Bearss et al., 2013; Bearss, Burrell, et al., 2018a; Burrell et al., 2020). This is crucial information considering other BPT studies show the level of parental adherence directly influences child outcomes and is necessary for children to generalize and maintain skills in the home (Stocco \& Thompson, 2015; Strauss et al., 2012). Studies have examined potential barriers to parents' use of behavioral strategies such as the interaction between children's and parents' behaviors (see Stocco \& Thompson, 2015, for a comprehensive review). For instance, a parent may inadvertently reinforce a challenging behavior that temporarily ends that behavior. In turn, the termination of the challenging behavior may reinforce the parents' behavior which creates a cycle that maintains both the parent's and child's behavior.

Studies have also shown that parents' views on the burden of behavioral treatments (Hock et al., 2015) and their barriers (MacNaughton \& Rodriguez, 2001) correlate to low levels of treatment adherence. In addition, increased stress has been shown to decrease parents' implementation of interventions (Nock \& Kazdin, 2001; Rovane et al., 2020). The latter is of particular concern given parents of autistic children typically experience higher levels of stress than parents of neurotypical children (Costa et al., 2017). Moreover, parents' decisions on their children's treatment can be affected by high levels of stress (Bonis, 2016). Therefore, it is paramount that researchers explore interventions to assist parents in overcoming barriers to implementation.

Acceptance and commitment training (ACT) is a processbased intervention that has shown to be effective in addressing various areas of psychological distress and well-being for parents of autistic children (see Byrne et al., 2021; Garcia et al., 2021; and Han et al., 2021, for comprehensive reviews). This approach suggests that many of the struggles parents face are a result of low psychological flexibility and high experiential avoidance (EA). Psychological flexibility within parenting may be defined as the ability of an individual to accept aversive emotional experiences (e.g., stress, anxiety) in relation to parenting while maintaining engagement in values-based behaviors such as improving their relationship with their child and using appropriate parenting skills (Whittingham \& Coyne, 2019) whereas EA is an attempt to escape unpleasant, verbally mediated psychological content (e.g., negative thoughts or painful feelings). Parents with low psychological flexibility and high EA tend to engage in unfavorable parenting strategies (e.g., severe discipline or inconsistent rules; Brown et al., 2014; Coyne et al., 2011). On the other hand, greater psychological flexibility and low EA in parents has been linked to compassionate interactions (Han et al., 2020; Wong et al., 2016), adaptive parenting practices, and lower levels of youth internalizing and externalizing problems (Brassell et al., 2016).

ACT interventions for parents of autistic children have shown significant improvement in parents' distress (Blackledge \& Hayes, 2006), stress (Corti et al., 2018; Fung et al., 2018; Lunsky et al., 2018), depression (Blackledge \& Hayes, 2006; Hahs et al., 2019 ; Joekar et al., 2016), and valuesbased behaviors (Gould et al., 2018) as well as children's prosocial behavior (Pennefather et al., 2018). However, quality of life, anxiety, and mindfulness scores did not reveal significant changes after the aforementioned ACT interventions (Hahs et al., 2019; Joekar et al., 2016). Lastly, substantial improvements were reported in parents' EA and values scores (Blackledge \& Hayes, 2006; Fung et al., 2018; Lunsky et al., 2018) with a lack of significant changes in cognitive fusion skills (Corti et al., 2018). In sum, ACT parent interventions have shown mixed results in addressing mental health difficulties in parents of autistic children (Byrne et al., 2021; Garcia et al., 2021). More research is needed to address areas such as the inclusion of clinical populations, utilization of online ACT protocols, integration of ACT into traditional BPTs, and the implementation of longer followup sessions.

Integration of $\mathrm{ACT}$ procedures with $\mathrm{BPT}$ in $\mathrm{ABA}$ parent interventions (Corti et al., 2018; Pennefather et al., 2018; Yi \& Dixon, 2021) and Stepping Stone Triple P (Brown et al., 2014, 2015; Whittingham et al., 2014, 2016) have produced significant improvements in children's behaviors and parents' well-being. Although limited, these studies show there are multiple advantages in supplementing traditional BPTs with ACT procedures. For example, traditional BPTs do not address parental inner states (e.g., feelings, thoughts, emotions) even though research shows that stress, anxiety, depression, quality of life, and shame are important predictors in parents' engagement in BPT (Chacko et al., 2016; Fenning \& Butter, 2019). Therefore, it stands to reason that clinicians could use ACT to assist parents in managing aversive private events and to ease the burden of parents implementing their children's behavior treatment. Second, the directive style used in traditional BPTs may create resistance for parents to follow through with behavioral strategies 
(Corti et al., 2018; Raulston et al., 2019; Yi \& Dixon, 2021). In fact, parents report that support from professionals and parent-professional collaboration, such as mutual trust, shared decision making, and affect-behavior integration, significantly improves intervention outcomes with parents (Raulston et al., 2019). The integration of ACT with BPT could encourage a collaborative relationship between parents and service providers through value-based goal setting and compassion. This blended approach could also promote concordance, a collective problem-solving approach to treatment development, over the traditional notion of adherence (see Dickinson et al., 1999, and Snowden et al., 2014, for an overview of concordance).

To date, only two published group studies have used online ACT-based interventions for parents with autistic children (Pennefather et al., 2018; Yi \& Dixon, 2021). Results revealed that combining ABA and ACT produced significant reductions in the parent-reported level of child hyperactivity, increases in parent knowledge, parental adherence, and improvements in children's prosocial behaviors. In addition, ABA online parent interventions have produced comparable results to traditional in-person training and significant changes in target behaviors (Tomlinson et al., 2018). Despite these positive outcomes, current reviews show that adherence to online ABA procedures is mixed and interventions are limited to particular target behaviors (e.g., aggression, self-injury, property destruction) and specific procedures such as functional communication training and preference assessments. There are important advantages of delivering evidence-based interventions online. For example, telehealth increases access to services in rural and remote areas, reduces travel time and health-care costs, improves comfort and flexibility of remote in-home consultation, and increases access when conducting research.

Thus far, only one online RUBI study (Burrell et al., 2020) and four online ACT parent studies (Pennefather et al., 2018; Rayner et al., 2016; Sairanen et al., 2019; Yi \& Dixon, 2021) have demonstrated significant improvements in children's behaviors and parental well-being. In addition, research has indicated that combining BPT and ACT improved parent-reported child challenging behaviors, child functional performance, parent confidence, family functioning, and parental conflict and each maintained at 6-month follow-ups (Brown et al., 2014, 2015; Whittingham et al., 2014, 2016). Despite promising results from the above-mentioned studies, more research is needed in several areas. For instance, this is the first study to date that has integrated ACT with the RUBI curriculum.

The purpose of this research was to address some of the missing gaps in the literature. First, this study included direct measures of parental implementation to determine if parents used behavioral strategies when introduced to
ACT + BPT. Second, it assessed the supplemental effects of ACT+BPT on parents' stress and EA. Third, this study evaluated the feasibility of ACT + BPT delivered online. Lastly, the study directly assessed the impact of parents' participation in ACT+BPT on decreasing children's challenging behaviors to determine whether intervention effects are due to changes in child functioning rather than parent perception (Whittingham et al., 2016).

\section{Method}

\section{Participants and Setting}

Participants were four parent-child dyads who were recruited via email from the waitlist of an ABA clinic in the southeastern region of the United States. The parent participants had to be at least 18 years old and have a child diagnosed with autism spectrum disorder (ASD). The children participants had to be between 5 and 12 years old, have a diagnosis of ASD, have moderate to advanced conversational skills, demonstrate either escape-maintained and/or attention-seeking challenging behaviors that are non-life-threatening or dangerous (as evidenced by a functional assessment interview conducted by the researcher), and have never received ABA or other behavioral interventions prior to the study. The participants were given pseudonyms to protect their confidentiality.

The study was conducted via real-time videoconferencing within the participants' homes. This allowed parents the opportunity to learn and demonstrate target skills in their natural environments while simultaneously practicing social distancing during the coronavirus (i.e., COVID-19) pandemic.

\section{Dyad 1 (Jessica and Lauren)}

Jessica was a 51-year-old, neurotypical, Caucasian mother who was married, had a graduate degree, and had no known mental health difficulties. She worked as an occupational therapist but worked reduced hours from home during COVID-19. Jessica had some exposure to mindfulness training prior to the study but reported she did not practice it. Her only daughter, Lauren, was 10 years old and had several comorbid diagnoses including ASD, attention-deficit/hyperactivity disorder (ADHD), oppositional defiant disorder (ODD), anxiety, trichotillomania, and other medical and language-related diagnoses. At the time of the study, Lauren was receiving occupational therapy (OT), physical therapy (PT), and counseling. 


\section{Dyad 2 (David and Walker)}

David was a 40-year-old, neurotypical, Caucasian, transgender father of two who was married, had a graduate degree, and had no known mental health difficulties. He was a counselor who worked primarily from home during COVID-19, but he occasionally went to an office. David reported he practiced mindfulness daily. His oldest son, Walker, was 7 years old and diagnosed with ASD, ADHD, and dyslexia. Walker received OT services.

\section{Dyad 3 (Samantha and Paul)}

Samantha was a 36-year-old, neurotypical, Caucasian mother of five who was married, had an undergraduate degree, and had no known mental health difficulties. She was a stay-at-home mom who homeschooled her children during COVID-19. Samantha reported having no training in or use of mindfulness prior to this study. Her second youngest child, Paul, was 6 years old. He had a diagnosis of ASD, and he received OT and speech therapy.

\section{Dyad 4 (Amanda and Zach)}

Amanda was a 35-year-old, neurotypical, Caucasian mother who was divorced, had an undergraduate degree, and had no known mental health difficulties. She worked in a pharmacy; thus, she continued to go to work during COVID-19. Amanda reported having no training or practice in mindfulness prior to this study. Her only son, Zach, was 11 years old and diagnosed with ASD, attention-deficit disorder (ADD), and dyspraxia. Zach received OT, PT, speech therapy, and counseling.

\section{Materials}

The study used Yondo, a HIPAA compliant real-time videoconferencing platform, to meet with participants. This allowed for screen sharing of training handouts. Participants' emails were also used to share copies of training handouts and homework as well as to schedule sessions.

The Open-Ended Functional Assessment Interview (Hanley, 2009) was used to assess the function of children's behaviors. This tool has been used to successfully identify challenging behaviors to target for reduction as well as pinpoint target behaviors deemed meaningful by children's parents (Hanley et al., 2014).

Parent Training for Disruptive Behaviors: The RUBI Autism Network, Clinician Manual (Bearss, Johnson, et al., 2018b) was used to teach parents' behavioral strategies. In particular, the chapters on prevention strategies, reinforcement, compliance training, and planned ignoring were used as they addressed key components of the three-term contingency. That is, prevention strategies addressed antecedent interventions, reinforcement focused on increasing replacement behaviors, and planned ignoring and compliance training dealt with two function-based consequences that addressed the primary functions of the children who participated in this study (i.e., attention and escape, respectively). The manual includes activity sheets for participants to practice identification of strategies and data collection, videos to illustrate examples and nonexamples of the procedures, and homework assignments to assist in the practice of the behavioral strategies with their children.

Stress Management for Parents: Acceptance and Commitment Therapy (Whittingham et al., 2010) was also used. This manual was specifically designed to teach ACT to parents of developmentally disabled children. It contains the script for the trainer to lead a discussion on the six processes while utilizing classic ACT metaphors and experiential activities. The manual also includes handouts that summarize information for parents, worksheets specific to values and committed actions, and homework assignments. It was modified from a 4-hr group parent training to a 2-hr individual training. The ACT component of the training also consisted of experiential activities and metaphors embedded into the BPT sessions. These scripts came from Acceptance and Commitment Therapy: The Clinician's Guide for Supporting Parents (Whittingham $\&$ Coyne, 2019). They demonstrated how ACT strategies could be used to cope with the private events that may be barriers to implementing behavioral strategies.

\section{Dependent Variables}

\section{Parents' Implementation}

This variable was a measure of whether participants used behavioral strategies with their children across various target routines such as schoolwork, chores, or bedtime routines. Implementation was measured as a percentage of skills completed on the behavioral implementation checklist (see Table 1). Each skill was marked as either a plus or minus depending on parents' demonstration of the skill at any point during the observation. For example, multiple prevention strategies were taught; yet only one prevention strategy needed to be demonstrated for a plus to be recorded. If no prompts were needed and/or no challenging behaviors occurred, the skill was marked as not applicable and was taken out of the total count used to calculate the percentage. Mastery of parents' implementation was $80 \%$ or higher across two consecutive sessions.

\section{Parents' Responsiveness to Training}

Responsiveness was measured by the percentage of demonstrated objectives/assignments during each portion 
Table 1 Behavioral strategies implemented by parents

\begin{tabular}{l}
\hline Behavioral Strategies \\
\hline Verbally identifies the target behavior to reinforce \\
Verbally identifies a reinforcer \\
Uses a minimum of one prevention strategy \\
Stands close to child and gains their attention prior to giving an \\
instruction \\
Gives directions as instruction rather than a question \\
Delivers reinforcer immediately after target behavior \\
Delivers reinforcer contingent on target behavior \\
Delivers reinforcer on a continuous schedule \\
Delivers specific praise \\
Prompts child to complete the instruction if the child does not \\
comply (if applicable) \\
Avoids physical touch during challenging behavior unless \\
prompting (if applicable) \\
Avoids eye contact with the child during challenging behaviors \\
(if applicable) \\
Avoids talking or responding to the child during challenging \\
behavior unless to prompt (if applicable)
\end{tabular}

of the training (i.e., ACT, BPT, and homework; see Table 2). Thus, three separate measures were collected. Responsiveness to ACT was measured by the percentage of demonstrated objectives during the ACT portion of the training. This was scored as either a 2 (i.e., the parent correctly demonstrated the learning objective in full), 1 (i.e., the parent partially demonstrated the learning objective), 0 (i.e., the parent did not demonstrate the learning objective), or not applicable (i.e., the objective was not covered in the session). Responsiveness to $B P T$ was also measured as a percentage of demonstrated objectives using the same criterion. These objectives are found in the RUBI curriculum. Lastly, responsiveness to homework was measured by the percentage of completed homework assignments from both the ACT and BPT portions of the training. This measure was scored as either a plus or minus depending on whether the entire homework sheet was completed.

\section{Children's Rate of Challenging Behavior}

Rate per minute of children's challenging behaviors was measured during target routines. Each child's target behavior was given an objective definition based on the functional assessment interview (see procedures for definitions and functions).

\section{Experiential Avoidance}

The Parental Acceptance and Action Questionnaire (PAAQ) is a process measure of parents' $\mathrm{EA}$ in the context of parenting (Cheron et al., 2009). It is a 15-item questionnaire in which parents rate the level to which they consider a statement true on a 7-point Likert scale. The PAAQ comprises two subscales: unwillingness to witness the child experiencing negative emotions (unwillingness subscale) and the parent's inability to effectively manage parental reactions to their child's affect (inaction subscale). The PAAQ is a valid report of EA when compared with several other reputable assessments such as the Acceptance and Action Questionnaire (AAQ-II; Cheron et al., 2009; Coyne et al., 2011).

\section{Stress}

The Perceived Stress Scale (PSS-10) is a 10-item outcome measure of one's experience of stress (Cohen et al., 1983). Scores range from 0 to 40 and fall into one of three categories: (1) 0-13 indicating low stress, (2) 14-26 denoting moderate stress, and (3) 27-40 signifying high stress. The PSS-10 has demonstrated acceptable psychometric properties across studies (Lee, 2012; Taylor, 2015). In particular, it has demonstrated minimum levels of internal consistency $(>0.70)$ and test-retest reliability ( $>0.70$ ) across 12 and 4 studies, respectively (Lee, 2012).

\section{Parents' Measure of Children's Challenging Behaviors}

A 4-point rating scale measured by parents rated the frequency and severity of their children's challenging behaviors each day. The frequency of the behaviors was rated as either None, Few, Some, or Several whereas the severity was rated as either None, Low, Moderate, or Severe. The simple rating scale allowed for an analysis of the children's behaviors when the researcher was not present while keeping parental response effort at a minimum.

\section{Social Validity}

A semi-structured interview was conducted at the end of the study to assess the parents' experience of the training, ease of learning, effectiveness of the approaches, generalization of the strategies, barriers faced, and most beneficial part of the training. This provided information on the acceptability of ACT+BPT.

\section{Reliability Measurements and Interobserver Agreement}

A second observer was trained on the data collection procedures by the researcher using behavior skills training (BST). Videos of a confederate and the researcher were used to train the second observer. The confederate demonstrated examples of challenging behaviors maintained by either escape or 
Table 2 Learning objectives for parents' responsiveness to training measure

ACT Objectives During ACT Session

Identifies "weapons" they previously used to combat the stress of being a parent of an autistic child

Identifies the short-term and long-term cost of using these "weapons"

Names 2 or 3 thoughts or emotions they struggle with when their child has challenging behaviors

Role-plays the passengers on the bus and names difficult thoughts or emotions that may hinder moving in a valued direction

Identifies at least 2 values within being a parent

Participates in the mindfulness of breath exercise and shares their experience in the debrief

Participates in the defusion exercise and shares their experience in the debrief

Identifies a defusion exercise they are willing to practice on their own

Participates in the leaves on a stream exercise and shares their experience in the debrief

Participates in the mindfulness of emotions exercise and shares their experience in the debrief

Gives one example of the values into action worksheet to identify acts, barriers, and possible solutions

ACT Objectives Embedded into BPT session

Participates in the parenting mindfulness meditation and shares their experience in the debrief

Participates in the time travel and new perspective exercise and shares their experience in the debrief

Participates in discussion on the swamp metaphor and shares committed actions they are willing to take

Participants in discussion on the jump metaphor and describes one of their committed actions in small steps

BPT Objectives During Prevention Strategies Session

Identifies ways they currently prevent challenging behaviors

Watches videos and provide suggestions for how the parent could prevent challenging behaviors

Identifies 1 or 2 new prevention strategies they are willing to try

BPT Objectives During Reinforcement Session

Provides examples of reinforcers they current use and identify new potential reinforcers

Watches videos and identifies "reinforcement rules" and provide suggestions for how the parent could follow rules

Participates in developing a homework plan using reinforcement

BPT Objectives During Planned Ignoring Session

Watches videos and identifies maintaining consequences of challenging behaviors

Watches videos and identifies rules for planned ignoring

Watches videos/listens to written vignettes and identifies three types of planned ignoring

Participates in developing a home plan using planned ignoring

Demonstrates planned ignoring via role-play

BPT Objectives During Compliance Training Session

Creates list of instructions the child is likely to follow

Creates list of instructions the child is not likely to follow

Watches videos and identifies correct and incorrect use of compliance training

Demonstrates steps of compliance training via role-play

Participates in developing a home plan using compliance training

Watches videos and identifies various intervention strategies learned throughout all lessons

Homework Objectives

ACT homework: Values worksheet

ACT homework: Actions worksheet

BPT homework: Antecedent management data sheet

BPT homework: Reinforcer practice worksheet

BPT homework: Planned ignoring data sheet

BPT homework: Compliance training worksheet

attention simulating the types of challenging behaviors that would be observed during the study. Within the same videos, the researcher demonstrated examples of how parents may respond to those challenging behavior. The second observer practiced data collection of parents' implementation and children's challenging behaviors until $90 \%$ agreement was reached.

The second observer assessed IOA for 33\% of all sessions via video recordings and assessed the reliability of the following measures: (1) parents' implementation, (2) 
parents' responsiveness to ACT, (3) parents' responsiveness to BPT, (4) parents' responsiveness to homework, (5) children's challenging behaviors, (6) researcher's treatment integrity of ACT, and (7) researcher's treatment integrity of BPT. Each measure was calculated as a percent agreement using trial-by-trial data except for the children's challenging behaviors. IOA for the children's challenging behaviors was calculated using an exact count-per-interval using 30-s intervals. The observers simultaneously collected IOA on all behaviors demonstrated during any given video (e.g., parents' implementation and children's challenging behaviors); however, if needed, they would rewatch sections of the video to ensure all behaviors were counted.

IOA for parents' implementation during baseline was 97.4\% (range: $92.3 \%-100 \%$ ) for Jessica, $93.5 \%$ (range: $84.6 \%-100 \%$ ) for David, $96.0 \%$ (range: $87.5 \%-100 \%$ ) for Samantha, and $97.0 \%$ (range: $85.6 \%-100 \%$ ) for Amanda. During intervention, the IOA was $100 \%$ for Jessica, $100 \%$ for David, 96\% (range: $87.5 \%-100 \%$ ) for Samantha, and $97.0 \%$ (range: $92.3 \%-100 \%$ ) for Amanda. In maintenance, the IOA score for each participant was $100 \%$. The IOA for parents' responsiveness to ACT, BPT, and homework was also $100 \%$ for all three measures across all participants.

IOA for the researchers' measure of the children's challenging behaviors was $100 \%$ for Lauren, $93.1 \%$ (range: 80\%-100\%) for Walker, $86.0 \%$ (range: $80 \%-100 \%$ ) for Paul, and $99.0 \%$ (range: $93.8 \%-100 \%$ ) for Zach. During intervention, IOA was 90\% (range: $80 \%-100 \%$ ) for Lauren, 95\% (range: $85.6 \%-100 \%$ ) for Walker, $100 \%$ for Paul, and $100 \%$ for Zach. In maintenance, the IOA score was $100 \%$ for Lauren, 91\% (range: 90\%-92.3\%) for Walker, 91\% (range: 83\%-100\%) for Paul, and 100\% for Zach.

Treatment integrity checklists were used to measure whether the researcher presented the training according to their manuals. Separate checklists were used for the ACT and BPT portions of the training. It was calculated as a percentage of correctly implemented steps. The researcher's treatment integrity for both ACT and BPT was 100\% across all four participants. That is, the researcher implemented all the steps of both training curriculums according to their design. Moreover, IOA for the researcher's treatment integrity was $100 \%$ across both parts of the training for each participant.

\section{Experimental Design}

The study used a concurrent multiple baseline across participants in which participants were randomly assigned to three tiers. It consisted of three phases: baseline, ACT+BPT, and maintenance probes at 1 week and 1 month. One- to 2-hr sessions occurred twice a week for 11 weeks, including maintenance. The 1-hr sessions occurred during baseline, posttraining, and maintenance whereas the three training sessions were $2 \mathrm{hr}$ each. Sessions consisted of parents demonstrating one target routine each session with their children. The training was completed by a Board Certified Behavior Analyst ${ }^{\circledR}(\mathrm{BCBA} \AA)$ with experience using ACT and BPT interventions with parents of autistic children.

\section{Procedures}

Informed consent was obtained by the researcher meeting with each participant individually via videoconferencing. Parent participants were given a copy of the written consent form and the researcher reviewed the procedures of the study with the participant. They were given time to ask questions. Next, assent was obtained by the researcher describing the study to the children participants. A visual aid was given to the children that highlighted their role in the study and their right to say no.

Next, the experimenter conducted the open-ended functional assessment interview to assess if the children engaged in either escape-maintained or attention-seeking behaviors. For Lauren and Zach, their challenging behaviors were verbal refusal defined as any instance of vocally refusing to comply with an instruction or arguing why they should not have to engage in the task (e.g., "I'm not going to do that" or "I don't need to"). The primary function of their behaviors was escape. Walker's challenging behavior was inappropriate attention-seeking. This was defined as any instance of seeking attention in socially inappropriate ways such as pushing or pulling on others, leaning on others, touching others with objects, talking to others when they have asked him not to, making noises, or crying. Paul's challenging behavior was to escape from tasks. This was defined as any instance of leaving the instruction, laying on his mom or the ground, or pushing/throwing the activity materials. This response class was maintained by both escape and attention.

During the functional assessment interview, parents were also asked to identify routines that typically evoked challenging behaviors from their children. These became the target routines that were used to assess parents' implementation of behavioral strategies as well as the children's rate of challenging behaviors.

\section{Baseline}

All participants completed the PAAQ and PSS-10 before their first session. They continued to complete these two measures at the end of every week throughout the study. During baseline sessions, participants were asked to demonstrate one target routine each session. A variety of target routines were used to reduce the likelihood of a practice effect on the children's behavior. The experimenter collected data on the parents' implementation of behavioral strategies and the children's rate of challenging behaviors during the target routines. Participants were instructed to complete the routines as they typically would without feedback from the researcher. The baseline condition continued 
until participants demonstrated stable responses. Baseline sessions lasted an hour or less depending on the length of the target routine.

\section{$\mathrm{ACT}+\mathrm{BPT}$}

This training sequence was introduced to participants as a packaged treatment (see Table 3). The intervention began with a 2-hr ACT training. During the training, the experimenter facilitated discussions that included the use of ACT metaphors and experiential activities. Participants were also given informational handouts on the training material. At the end of the training, participants were given homework assignments to further explore values and committed actions specific to parenting an autistic child.

In the next session, participants began BPT. The first training day contained lessons on prevention strategies and reinforcement; the second training day addressed compliance training and planned ignoring. The BPT consists of explanations and examples of each behavioral concept. This was paired with parent handouts, video vignettes, and homework assignments. The training was interactive and allowed for parents to discuss topics, ask questions, and role-play the material. The training segments lasted approximately $1 \frac{1}{2} \mathrm{hr}$. Each parent was provided the same training even though not all of the lessons pertained to the specific function of their child's target behavior (i.e., the function may have been escape only, but parents received both planned ignoring and compliance training). Yet, all the parents were able to describe how the lessons related to other various behaviors their children demonstrated.

Following each BPT lesson, an ACT experiential activity or metaphor was used to facilitate how ACT strategies could be used to cope with the challenges of implementing the behavioral strategies. This was presented immediately before asking parents to implement the newly learned skills with their children in a target routine. During the routine, the researcher collected data on the parent's implementation and the children's rate of challenging behaviors. Feedback was given to the parents at the end of the routine on the areas covered thus far in training. That is, on day 1, participants only received feedback on areas covered in training on that day. However, for the remainder of the study, participants received feedback on all areas covered in the 2 days of training. The target routines and feedback took the remaining $30 \mathrm{~min}$ of those $2-\mathrm{hr}$ sessions.

Once all three parts of the training were complete, the remaining sessions lasted $1 \mathrm{hr}$. Those sessions started with an embedded

Table 3 ACT+BPT Lessons

\begin{tabular}{|c|c|c|c|}
\hline Session & Topics & Activities & Explanation \\
\hline 1 & $\begin{array}{l}\text { Stress Management } \\
\text { for } \\
\text { Parents: ACT }\end{array}$ & $\begin{array}{l}\text { The struggle } \\
\text { Passengers on the bus } \\
\text { Values } \\
\text { Mindfulness } \\
\text { Putting values into action } \\
\text { Homework set-up }\end{array}$ & $\begin{array}{l}\text { To introduce parents to mindfulness as a strategy for managing the } \\
\text { stress of parenting in order to move them towards their values. }\end{array}$ \\
\hline \multirow[t]{3}{*}{2} & Prevention strategies & $\begin{array}{l}\text { Categories of prevention strategies } \\
\text { Video vignettes } \\
\text { Homework set-up }\end{array}$ & $\begin{array}{l}\text { To identify successful prevention strategies the parents are cur- } \\
\text { rently using and to add new prevention strategies they are willing } \\
\text { to try. }\end{array}$ \\
\hline & Reinforcement & $\begin{array}{l}\text { Identifying reinforcers } \\
\text { How to select a reinforcer } \\
\text { How to use reinforcement to change } \\
\text { behavior } \\
\text { Video vignettes } \\
\text { Homework set-up }\end{array}$ & $\begin{array}{l}\text { To assist parents in identifying potential reinforcers and to teach } \\
\text { them how to use reinforcement to increase desired behaviors. }\end{array}$ \\
\hline & ACT exercise & Parenting: A mindfulness meditation script & $\begin{array}{l}\text { To orient parents to the present moment as an antecedent interven- } \\
\text { tion for them to use prevention strategies as well as prompt } \\
\text { acceptance of aversive events that may otherwise inhibit effective } \\
\text { parenting strategies. }\end{array}$ \\
\hline \multirow[t]{3}{*}{3} & Planned ignoring & $\begin{array}{l}\text { Implementing planned ignoring } \\
\text { Video vignettes } \\
\text { Role-play } \\
\text { Homework set-up }\end{array}$ & $\begin{array}{l}\text { To teach parents how to use planned ignoring to decrease } \\
\text { attention-seeking behaviors. }\end{array}$ \\
\hline & Compliance training & $\begin{array}{l}\text { Steps for compliance training } \\
\text { Video vignettes } \\
\text { Role-play } \\
\text { Homework set-up }\end{array}$ & To teach parents how to prompt and reinforce compliance. \\
\hline & ACT exercise & Time travel and take new perspective & $\begin{array}{l}\text { To prompt parents to perspective-take future scenarios to increase } \\
\text { the motivative augmental of values that increase the likelihood of } \\
\text { parents engaging in reinforcement. }\end{array}$ \\
\hline
\end{tabular}


ACT experiential activity or metaphor followed by a brief discussion. Next, participants were asked to demonstrate a target routine with their children. Parents were provided with feedback at the end of the routine. These sessions continued until participants reached the mastery criterion for parental implementation.

\section{Maintenance}

Maintenance was assessed 1 week and 1 month after mastery. The first maintenance measure was parents' implementation of behavioral strategies during target routines. During maintenance sessions, there were no ACT experiential activities or metaphors prior to the start of the target routine. However, feedback was provided at the end of the demonstrations. The children's rate of challenging behaviors was also measured during these routines. Participants were asked to rate their children's challenging behaviors at the end of every evening for the entire week during weeks of the 1-week and 1-month maintenance. In addition, parents were given the PAAQ and the PSS10 at the end of the 1-week and 1-month follow-up. In the last session, participants were given a social validity interview.

\section{Debrief}

Participants were given a debrief session at the end of the study. The researcher gave parents access to various ACT, ABA, and community resources considering participants were on a waitlist to receive ABA services. As such, they needed additional resources to continue their training on BPT and ACT strategies.

\section{Results}

\section{Parents' Implementation}

Parents' implementation of behavioral strategies is shown in Fig. 1. In baseline, all four parents demonstrated stable, low levels of implementation. The average implementation was $25.9 \%$ (range: $22.2 \%-33.3 \%$ ) for Jessica, $28.7 \%$ (range: $23.1 \%-38.5 \%$ ) for David, $33.4 \%$ (range: $15.4 \%-53.8 \%$ ) for Samantha, and $30.4 \%$ (range: $16.7 \%-38.5 \%$ ) for Amanda.

As soon as the intervention was introduced, there was an immediate, increasing trend across implementation for all participants. The average implementation for Jessica increased to $74.4 \%$ (range: $38.5 \%-100 \%$ ). There was greater variability during this condition compared to baseline; however, this is due to the fact that the first data point was well below the mastery criterion. Yet, implementation for Jessica quickly increased and mastery was demonstrated within three sessions. The overall highest implementation average in this condition was $89.3 \%$ (range 83.3\%-100\%) for David. Implementation immediately increased to mastery level. The average implementation for Samantha in this condition was $81.6 \%$ (range: 69.2\%-92.3\%), and mastery was reached within three sessions. Likewise, the average implementation for Amanda increased to $86.4 \%$ (range: $67 \%-100 \%$ ), and she also demonstrated mastery within three sessions. In addition to an immediate increasing trend in implementation across all participants, there were no overlapping data points across baseline and intervention conditions.

During the 1-week follow-up, implementation for Jessica fell below the mastery criterion to $66.7 \%$. Yet, there was a return to mastery-level implementation at the 1-month follow-up with a score of $100 \%$. David, Samantha, and Amanda each demonstrated 100\% implementation at the 1 -week maintenance check. At the 1-month follow-up, David and Samantha maintained mastery-level implementation, but there was a slight drop in both percentages. Implementation for Amanda was maintained at $100 \%$ during the 1-month follow-up.

\section{Children's Rate of Challenging Behaviors}

Figure 1 also shows the children's rate of challenging behaviors. During baseline, challenging behaviors for Lauren were at stable, low levels $(M=0.1, S D=0.2)$. There were variable rates of responding for Walker, Paul, and Zach. The average rate per minute was $0.5(S D=0.5)$ for Walker, 1.4 $(S D=0.9)$ for Paul, and $0.4(S D=0.5)$ for Zach. Variable responding continued for each child participant during the intervention condition. Lauren demonstrated an immediate increase in challenging behaviors followed by a decreasing trend back toward baseline levels $(M=0.8, S D=0.5)$. Walker $(M=0.7, S D=1.1)$, Paul $(M=0.2, S D=0.3)$, and Zach $(M=0.2, S D=0.2)$ each initially demonstrated low levels of challenging behaviors at or below baseline levels. However, for those three participants, there was a rise in the third data point, which resulted in an overall increasing trend during the intervention.

During the 1-week follow-up, there were zero instances of challenging behaviors by Paul. The rates of challenging behaviors for Walker and Zach were at the low end of their baseline range. In contrast, Lauren had increased responses compared to baseline. However, at the 1-month follow-up, Lauren had zero instances of challenging behaviors. Lastly, the rate of challenging behavior for Walker and Zach maintained at the same level during the 1-month follow-up. 
Fig. 1 Left panel shows parent's implementation of behavioral strategies during target routines. Right panel shows direct measure of the children challenging behaviors during target routines

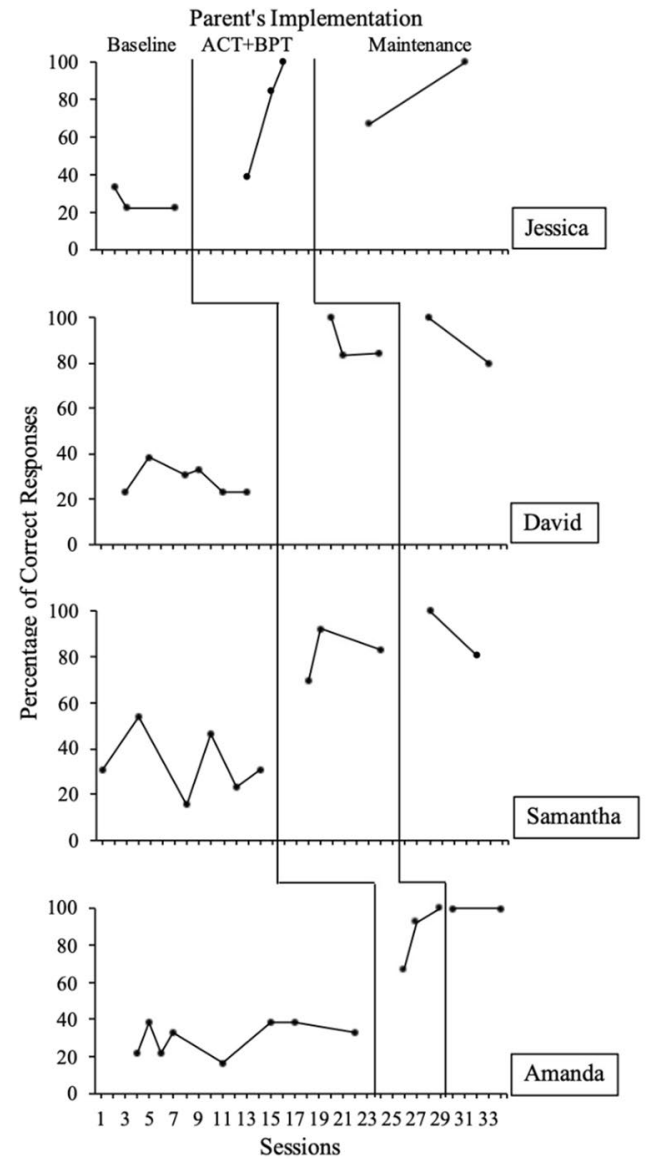

However, Paul demonstrated an increase in responding which was within the baseline range.

\section{Parents' Responsiveness to Training}

Jessica, David, Samantha, and Amanda each demonstrated $100 \%$ responsiveness to ACT. That is, every parent met all of the learning objectives for this part of the training. A similar trend was seen in the responsiveness to the BPT. Again, each parent participant demonstrated $100 \%$ responsiveness to the BPT learning objectives. Participants were not as responsive to homework. Jessica was the only participant with $100 \%$ responsiveness to the ACT and BPT homework. David and Samantha each completed $100 \%$ of the ACT homework, but only $50.0 \%$ of the BPT homework for a total of $66.7 \%$ of all homework assignments. Amanda completed only $33.3 \%$ of the total homework. She completed $100 \%$ of the ACT homework and $0.0 \%$ of the BPT homework.

\section{PAAQ and PSS-10}

PAAQ scores are shown in Table 4. During baseline, each participant had moderate amounts of EA as evidenced by their PAAQ scores. After the intervention, there was a decrease in scores by Jessica and David. At the 1-week follow-up, Jessica continued to show a decrease in EA whereas David, Samantha, and Amanda maintained scores similar to their intervention averages. During the 1-month follow-up, David and Amanda demonstrated a slight decrease in EA. In contrast, scores for Jessica and Samantha showed a slight increase in EA compared to intervention levels. Thus, Jessica, David, and Amanda demonstrated an overall decrease from baseline to 1-month follow-up.

PSS scores are also found in Table 4. At baseline, Jessica had high levels of stress, David and Amanda both had moderate levels of stress, and Samantha had low levels of stress according to the PSS-10 scoring. Upon intervention, Jessica demonstrated a decrease in PSS scores moving her rating from high to moderate levels of stress. In contrast, David showed a slight increase in the average stress scores during the intervention. Samantha and Amanda maintained stress scores that were comparable to baseline. At the 1-week follow-up, there was a decrease in stress scores for Jessica, David, and Amanda. Likewise, scores for those three participants remained low at 1-month follow-up. Scores for Samantha remained consistent from baseline to 1-week follow-up, yet she showed a slight increase in stress at the 1-month follow-up. 
Table 4 PAAQ and PSS-10

Scores

\begin{tabular}{|c|c|c|c|c|c|c|c|c|c|c|c|c|}
\hline \multirow[t]{3}{*}{ Participants } & \multicolumn{6}{|c|}{ PAAQ } & \multicolumn{6}{|c|}{ PSS-10 } \\
\hline & \multicolumn{2}{|c|}{ Baseline } & \multicolumn{2}{|c|}{$\mathrm{ACT}+\mathrm{BPT}$} & \multirow{2}{*}{$\begin{array}{l}\text { 1-week } \\
\text { follow- } \\
\text { up } \\
\text { M }\end{array}$} & \multirow{2}{*}{$\begin{array}{l}\text { 1-month } \\
\text { follow-up } \\
\text { M }\end{array}$} & \multicolumn{2}{|c|}{ Baseline } & \multicolumn{2}{|c|}{$\mathrm{ACT}+\mathrm{BPT}$} & \multirow{2}{*}{$\begin{array}{l}\text { 1-week } \\
\text { follow- } \\
\text { up } \\
\text { M }\end{array}$} & \multirow{2}{*}{$\begin{array}{l}\text { 1-month } \\
\text { follow- } \\
\text { up } \\
\text { M }\end{array}$} \\
\hline & M & SD & M & SD & & & M & SD & M & SD & & \\
\hline Jessica & 66 & (1.4) & 59 & $(4.9)$ & 52 & 54 & 32 & $(0.0)$ & 24 & $(4.0)$ & 20 & 20 \\
\hline David & 45 & (4.1) & 38 & $(5.7)$ & 38 & 28 & 21 & (3.4) & 22 & (1.4) & 13 & 13 \\
\hline Samantha & 51 & (4.6) & 51 & $(0.7)$ & 52 & 54 & 12 & (4.8) & 13 & $(0.0)$ & 13 & 16 \\
\hline Amanda & 63 & (2.3) & 62 & (5.1) & 63 & 53 & 22 & (1.6) & 22 & (1.5) & 18 & 15 \\
\hline
\end{tabular}

\section{Parents' Measure of Children's Behaviors}

\section{Frequency}

There was a slight decrease in the average frequency of the parents' report of their children's challenging behaviors for each child participant between baseline and intervention (see Fig. 2). The average frequency of challenging behaviors for Lauren, Walker, and Paul further decreased between baseline and the 1-week follow-up. On the other hand, the average frequency of challenging behaviors increased for Zach, which surpassed that of baseline. At the 1-month follow-up, the average frequency of challenging behaviors for Lauren, Walker, and Zach decreases beyond that of baseline, intervention, and 1-week follow-up whereas the average frequency for Paul increased at 1-month follow-up, which returned challenging behaviors to baseline average.

\section{Severity}

There was a decrease in the parents' reports of the average severity of their children's challenging behaviors for Walker, Paul, and Zach between baseline and the intervention (see Fig. 2). In contrast, a slight increase was observed in the average severity of challenging behaviors for Lauren. The average severity of challenging behaviors decreased for Lauren and Walker at 1-week follow-up whereas there was no change in average severity for Paul between intervention and 1-week follow-up. The average severity of challenging behaviors for Zach increased slightly returning to a similar average as the baseline. Lastly, at 1-month follow-up, a significant decrease in the severity of challenging behaviors was observed for Lauren, Walker, and Zach. On the other hand, an increase in average severity returned challenging behaviors to baseline for Paul during the 1-month follow-up.

\section{Social Validity}

Overall, parents reported the training as a positive experience. In addition, they all reported that BPT material was easy to learn with parts of it being a review. They also reported the strategies were effective in addressing their children's challenging behaviors. Moreover, every parent reported the training material was easy to generalize. Some of the concerns that participants discussed were the amount of the training material in a short period, homework, and the effects of other people during training. As for the ACT portion, only Amanda found ACT difficult to learn. In particular, she reported struggling with the concept of acceptance of stress. Yet, she, along with the others, found ACT effective in addressing their psychological distress as parents. Likewise, everyone reported they were able to generalize the ACT skills to other areas of their life such as work or peer relationships. Two parents reported ACT as the most beneficial part of the overall training experience whereas one reported that planned ignoring and mindfulness were jointly important in addressing her concerns as a parent.

\section{Discussion}

Results suggest that ACT+BPT was an effective package for increasing parents' implementation of behavioral strategies. In addition, the training facilitated the maintenance of behavioral strategies at the mastery level in all participants. Parents demonstrated mastery of behavioral strategies despite the fact that three of the parents had low responsiveness to the homework portion of the BPT training. This suggests homework may not be a critical component of BPT.

Data also indicated that ACT+BPT was an efficient package considering all parents mastered implementation within three sessions. That is, parents mastered the material with only $2 \mathrm{hr}$ of ACT, $4 \mathrm{hr}$ of BPT, and three target routines with feedback. This is a brief training considering that none of the parents had exposure to ABA training prior to the study (see Hahs et al., 2019; Pennefather et al., 2018, for similar results). This shows the training could be beneficial as a brief parent training for those who are unable to access on-going behavior analytic services (e.g., families on a waitlist or in remote areas) considering the families are 


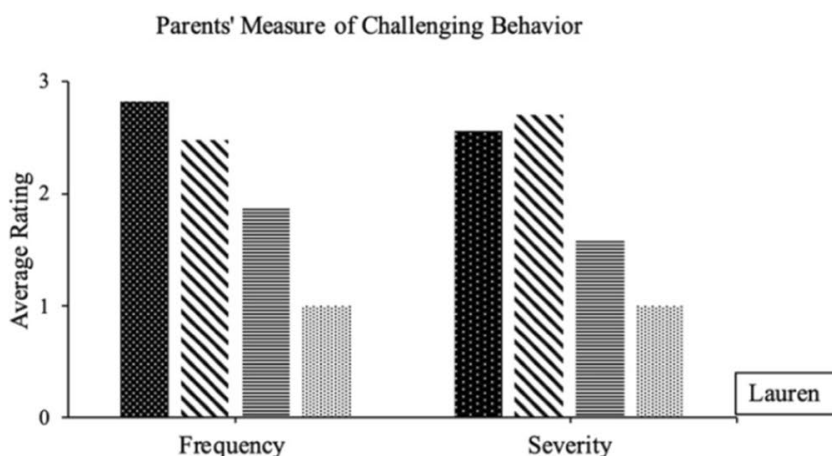

Parents' Measure of Challenging Behavior

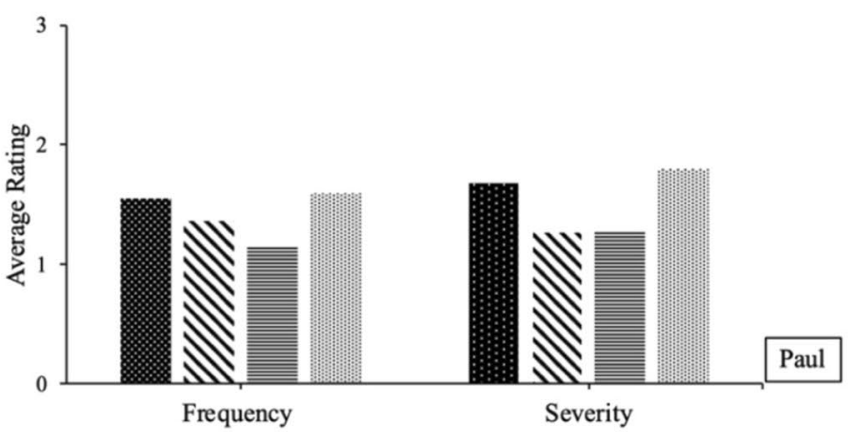

Parents' Measure of Challenging Behavior

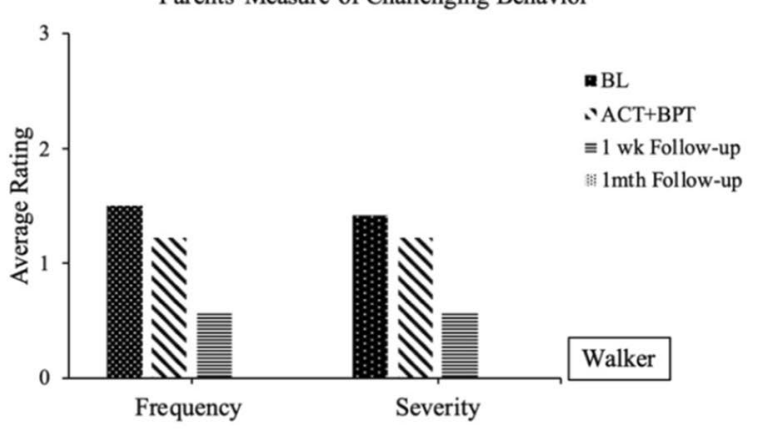

Parents' Measure of Challenging Behavior

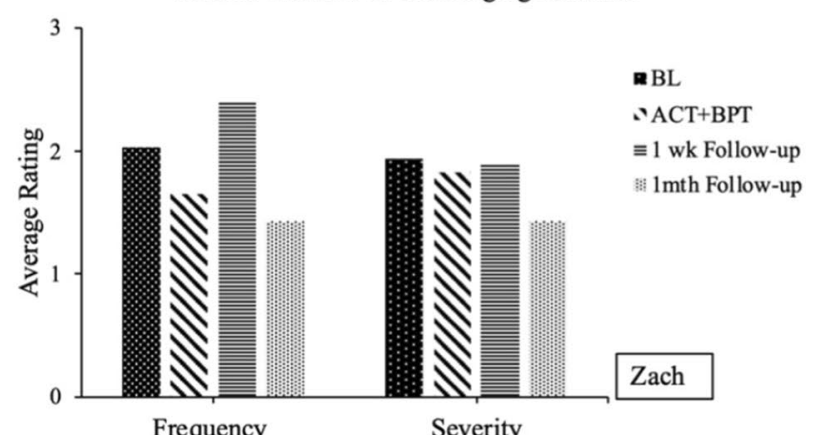

Fig. 2 Average parental rating of their children's challenging behaviors across each condition in which 0 is none, 1 is few/low, 2 is some/moderate, 3 is several/severe

not struggling with severe challenging behaviors that could be life threatening or dangerous (see Leijten et al., 2021)

Three participants (Jessica, David, and Amanda) demonstrated moderate to large decreases in their PAAQ scores between baseline and 1-month follow-up. These results support previous research in improving parental EA at posttest (Blackledge \& Hayes, 2006; Fung et al., 2018; Hahs et al., 2019); however, it presents some differences. In this study, two participants continued to show decreases in EA at the 1-month follow-up whereas the other two participants had little change in EA at this same point in time. In previous research, EA remained low across all participants at 3-month follow-ups (Blackledge \& Hayes, 2006; Fung et al., 2018). Three potential factors may explain these differences. First, in the two previously mentioned studies researchers used a general measure of EA (i.e., AAQ-II) whereas in this study, a context-specific measure of parental EA was implemented (Byrne et al., 2021). There may have been a lack of treatment sensitivity in the PAAQ (i.e., scores on a measure changing as a result of an intervention; Ong et al., 2019) which could have affected parents' EA at follow-up. Second, previous research suggests there can be a delay in the effects of ACT (Blackledge \& Hayes, 2006; Han et al., 2020, 2021), which is likely due to parents building familiarity and experience with ACT skills. Therefore, additional follow-up measures may have produced different results. Third, there were several contextual differences among participants (e.g., number of children, the influence of COVID-19 on their work, marital status). These differences could affect the degree of aversive private events that each parent experienced that in turn affect the level of each participants' EA.

Parental stress also showed mixed results across participants. Jessica, David, and Amanda demonstrated an overall decrease in their stress from baseline to 1-month followup. Yet, Samantha demonstrated little to no change in her stress scores between baseline and 1-week follow-up and an increase in stress at the 1-month follow-up. It is worth noting that according to the PSS-10 scoring Samantha had low levels of stress throughout the study. On the other hand, the other participants each had high to moderate levels of stress. Thus, ACT+BPT appears to be overall effective in reducing moderate and high levels of parental stress.

It is interesting that significant changes in parental stress have been reported in studies using online ACT+ABA (Pennefather et al., 2018) and online RUBI (Postorino et al., 2017). Yet, other studies using BPT interventions alone have had small or even negative effects on parents' stress (Strauss et al., 2012; Tarver et al., 2019). Those results seem to indicate that parental stress may decrease when parents receive BPT alone (i.e., without the addition of ACT); however, in some cases, parental stress may increase when parents receive BPT only. Although results 
in this study are preliminary, they suggest that adding mindfulness and values-based interventions to traditional BPTs may reduce parental stress (Whittingham \& Coyne, 2019).

Parents also rated the severity and frequency of children's challenging behaviors over the course of the study. Lauren's, Walker's, and Zach's parents each reported a decrease in the frequency and severity of challenging behaviors from baseline to the final follow-up. Paul showed a decrease in challenging behaviors until his 1-month follow-up in which he had a return to baseline. Yet, this higher average may have been the result of fewer data points in this condition compared to those in baseline or ACT+BPT. Thus, the rating scale may have been overly sensitive to an outlier datum in which there were more challenging behaviors than usual on a given day. Nonetheless, this general finding is in line with other research in which parents reported a decrease in their children's challenging behaviors after participating in RUBI training (Bearss et al., 2013; Bearss, Burrell, et al., 2018a; Bearss, Johnson, et al., 2015b; Edwards et al., 2019; Scahill et al., 2016). The results of the current research also correspond to those from an online, ABA parent training supplemented with ACT (Pennefather et al., 2018). In that study, the parents also reported their children's challenging behaviors reduced after training.

Direct observation data of children's behaviors showed either a large amount of variability or low rates of challenging behavior during baseline. It is interesting that a recent systematic review revealed that over half (55\%) of studies showed variability in the children's baseline behaviors (Ferguson et al., 2019). That is, the studies were unable to show stable levels or trends in the children's behaviors. Therefore, the variability in children's challenging behaviors observed in this study, although not ideal experimentally, was typical. Response variability could have been caused by reactivity to the researcher and/or the videoconferencing screen (Lerman et al., 2020); although, the researcher attempted to minimize reactivity by turning off the audio and video screen during the target routines. The variability could have also been a result of the different target routines selected each session. Additional intervention factors that were not controlled for during the study could have played a role in the variability of the children's behavior. For instance, some of the target routines may have been daily activities that allowed for practice between sessions whereas other routines were completed intermittently. Another example could be individual family variables such as the parent-child relationship or contingencies provided by a second parent or sibling.

Lastly, the role of comorbid diagnosis may have played a role in the effects of ACT + BPT on children's challenging behaviors. For example, previous data show children with ADHD, ODD, and anxiety made smaller improvements in noncompliance and other challenging behaviors when compared to children without those comorbid diagnoses (Lecavalier et al., 2017). In this study, only Paul, who had a sole diagnosis of ASD, demonstrated substantial decreases in the direct observation of his challenging behaviors. This minor factor could explain some of the differences in challenging behaviors and warrants additional research.

This study also adds to the evidence of the online delivery of parent training to improve parental well-being and decrease children's challenging behaviors. Results were in line with other research that found the remote use of the RUBI curriculum improved parenting skills and reduced children's challenging behaviors (Bearss, Burrell, et al., 2018a; Burrell et al., 2020). ACT studies have also shown to be effectively delivered online with parents (Pennefather et al., 2018; Rayner et al., 2016; Sairanen et al., 2019; Yi \& Dixon, 2021), however, they often lack direct measures of child and parent behavior (see Garcia et al., 2021; Han et al., 2021). Yet, overall, results from this study and previous research show that parents' implementation of behavioral strategies and well-being can improve after online $\mathrm{ACT}+\mathrm{BPT}$.

In addition, this is one of a few single-case design studies using ACT for parents of autistic children (see Gould et al., 2018, for another example). Single-case design studies are useful in a practice setting because they require less infrastructure, are more cost-effective, and need fewer resources to implement than group design studies (Ledford et al., 2019). In addition, with the current trend towards process-based therapies, using single-case designs provides important information on the specific processes of change. Isolating successful components of treatment and utilizing interventions specifically linked to processes of change (e.g., values-based interventions) may help reduce treatment failure (Hofmann \& Hayes, 2019; Unholz-Bowden et al., 2020). Thus, future research should continue using single-case designs to examine the effects of $\mathrm{ACT}+\mathrm{BPT}$ on directly measured outcomes for parents and autistic children.

\section{Limitations and Future Research}

This study presents several limitations, but we have chosen to discuss the five most salient. First, combining $\mathrm{ACT}+\mathrm{BPT}$ showed positive effects; nevertheless, it is difficult to conclude which components produced what effects. A component analysis or group comparison is needed to determine the degree to which ACT plays a role in increasing parental implementation of behavioral strategies. A component analysis of the BPT portion of the training would also be beneficial considering parents mastered implementing behavioral strategies despite their low engagement with BPT homework. Second, significant variability in the children's challenging behaviors 
during baseline and intervention made it difficult to determine the effectiveness of the intervention on their behavior. Variables such as reactivity to the researchers, comorbid diagnosis, and varying target routines may have affected the stability of challenging behaviors across the study. Future research could consider various ways to control for these variables such as adding more baseline sessions to decrease reactivity. Moreover, future studies could continue examining multiple direct and indirect parent and child measures such as the parents' use of behavioral strategies in community settings, the children's engagement in challenging behaviors not directly targeted, and the bidirectional effects of psychological flexibility on observable behaviors. Third, this study examined parents' responsiveness to ACT learning objectives and changes in EA; however, it does not further measure parents' engagement with the ACT processes. As such, there is no measure as to whether parents are using ACT strategies when parenting. Therefore, future research may consider measuring how often parents practice ACT strategies such as defusion or self-as-context exercises. Fourth, only 4 of the 11 lessons from the RUBI curriculum were used in this study. Thus, future research may consider examining if integrating ACT into the entire RUBI curriculum may further advance the findings from this study. Lastly, this study could have benefited from longer maintenance checks such as 3 to 6 months. This may have provided additional information on the effects of ACT+BPT on the long-term effects of parents' implementation, children's behaviors, and parental EA and stress.

\section{Conclusions}

Results suggest that ACT + BPT may be an ideal training package to support parents of autistic children in implementing their children's treatment. This study adds to the emerging research combining ACT components with BPTs such as ABA (Corti et al., 2018; Pennefather et al., 2018; Yi \& Dixon, 2021) and Stepping Stones Triple P (Brown et al., 2014, 2015; Whittingham et al., 2016). Current reports show that using BPT alone can produce moderate effects in decreasing parental stress (Postorino et al., 2017; Tarver et al., 2019). Therefore, adding ACT seems a useful strategy to enhance their effectiveness in reducing stress (see Whittingham, 2015, and Whittingham \& Coyne, 2019, for similar recommendations).

In addition, this study contributes to the utility of $\mathrm{ACT}+\mathrm{BPT}$ in improving children's behaviors even though the results are mixed. For instance, the majority of RUBI and ACT parent studies have used groups designs. In those studies, children's challenging behaviors have been reported either via questionnaires or parent reports (Bearss, Burrell, et al., 2015a; Byrne et al., 2021). Measuring children's behaviors directly provides important insight into the functional relationship between the intervention and problem behaviors as well as the environmental factors that influence those changes.

Availability of Data and Material Data are included within the manuscript.

Code Availability Not applicable.

Authors' Contribution The study was conceptualized by all the authors. Next, the first author conducted the study and wrote the manuscript. Lastly, all authors contributed to editing the manuscript.

Funding No funds, grants, or other support was received.

\section{Declarations}

Conflicts of Interest The authors have no conflicts of interest to declare that are relevant to the content of this article.

Ethical Approval This study was performed in line with the principles of the Declaration of Helsinki. Approval was granted by the first author's governing Institutional Review Board.

Consent to Participate Informed consent was obtained from all individual participants included in the study.

\section{References}

Argumedes, M., Lanovaz, M. J., \& Larivée, S. (2018). Brief report: Impact of challenging behavior on parenting stress in mothers and fathers of children with autism spectrum disorders. Journal of Autism \& Developmental Disorders, 48(7), 2585-2589. https:// doi.org/10.1007/s10803-018-3513-1

Bearss, K., Johnson, C., Handen, B., Smith, T., \& Scahill, L. (2013). A pilot study of parent training in young children with autism spectrum disorders and disruptive behavior. Journal of Autism \& Developmental Disorders, 43(4), 829-840. https://doi.org/10. 1007/s10803-012-1624-7

Bearss, K., Burrell, T. L., Stewart, L., \& Scahill, L. (2015a). Parent training in autism spectrum disorder: What's in a name? Clinical Child \& Family Psychology Review, 18(2), 170-182. https://doi. org/10.1007/s10567-015-0179-5

Bearss, K., Johnson, C., Smith, T., Lecavalier, L., Swiezy, N., Aman, M. ... Scahill, L. (2015b). Effect of parent training vs parent education on behavioral problems in children with autism spectrum disorder: A randomized clinical trial. Journal of the American Medical Association, 21(15), 1524-1533. https://doi.org/10.1001/ jama.2015.3150

Bearss, K., Burrell, T. L., Challa, S. A., Postorino, V., Gillespie, S. E., Crooks, C., \& Scahill, L. (2018a). Feasibility of parent training via telehealth for children with autism spectrum disorder and disruptive behavior: A demonstration pilot. Journal of Autism \& Developmental Disorders, 48(4), 1020-1030. https://doi.org/10. 1007/s10803-017-3363-2 
Bearss, K., Johnson, C., Handen, B., Butter, E., Lecavalier, L., Smith, T., \& Scahill, L. (2018b). Parent training for disruptive behaviors: The RUBI autism network, clinician manual. Oxford University Press.

Blackledge, J. T., \& Hayes, S. (2006). Using acceptance and commitment training in the support of parents of children diagnosed with autism. Child \& Family Behavior Therapy, 28, 1-18. https://doi. org/10.1300/J019v28n01_01

Bonis, S. (2016). Stress and parents of children with autism: A review of literature. Issues in Mental Health Nursing, 37(3), 153-163. https://doi.org/10.3109/01612840.2015.1116030

Botha, M., Hanlon, J., \& Williams, G. L. (2021). Does language matter? Identity-first versus person-first language use in autism research: A response to Vivanti. Journal of Autism \& Developmental Disorders, 20, 1-9. https://doi.org/10.1007/s10803-020-04858-w

Brassell, A. A., Rosenberg, E., Parent, J., Rough, J. N., Fondacaro, K., \& Seehuus, M. (2016). Parent's psychological flexibility: Associations with parenting and child psychosocial well-being. Journal of Contextual Behavioral Science, 5(2), 111-120. https://doi.org/ 10.1016/j.jcbs.2016.03.001

Brown, F. L., Whittingham, K., \& Sofronoff, K. (2014). Parental experiential avoidance as a potential mechanism of change in parenting intervention for parents of children with pediatric acquired brain injury. Journal of Pediatric Psychology, 40, 464-474. https://doi. org/10.1093/jpepsy/jsu109

Brown, F. L., Whittingham, K., Boyd, R. N., McKinlay, L., \& Sofronoff, K. (2015). Does Stepping Stones Triple P plus acceptance and commitment therapy improve parent, couple, and family adjustment following paediatric acquired brain injury? A randomized controlled trial. Behaviour Research \& Therapy, 73, 58-66. https://doi.org/10.1016/j.brat.2015.07.001

Burrell, T. L., Postorino, V., Scahill, L., Rea, H. M., Gillespie, S., Evans, A. N., \& Bearss, K. (2020). Feasibility of group parent training for children with autism spectrum disorder and disruptive behavior: A demonstration pilot. Journal of Autism \& Developmental Disorders, 50, 3883-3894. https://doi.org/10.1007/ s10803-020-04427-1

Byrne, G., Ghráda, Á. N., O’Mahony, T., \& Brennan, E. (2021). A systematic review of the use of acceptance and commitment therapy in supporting parents. Psychology \& Psychotherapy: Theory, Research \& Practice, 94, 378-407. https://doi.org/10.1111/papt. 12282

Chacko, A., Jensen, S. A., Lowry, L. S., Cornwell, M., Chimklis, A., Chan, E., Lee, D., \& Pulgarin, B. (2016). Engagement in behavioral parent training: A review of the literature and implications for practice. Clinical Child \& Family Psychology Review, 19, 204-215. https://doi.org/10.1007/s10567-016-0205-2

Cheron, D. M., Ehrenreich, J. T., \& Pincus, D. B. (2009). Assessment of parental experiential avoidance in a clinical sample of children with anxiety disorders. Child Psychiatry \& Human Development, 40, 383-403. https://doi.org/10.1007/s10578-009-0135-z

Cohen, S., Kamarck, T., \& Mermelstein, R. (1983). A global measure of perceived stress. Journal of Health \& Social Behavior, 24, 385-396. https://doi.org/10.2307/2136404

Corti, C., Pergolizzi, F., Vanzin, L., Cargasacchi, G., Villa, L., Pozzi, M., \& Molteni, M. (2018). Acceptance and commitment therapyoriented parent-training for parents of children with autism. Journal of Child \& Family Studies, 27(9), 2887-2900. https://doi.org/ 10.1007/s10826-018-1123-3

Costa, A. P., Steffgen, G., \& Ferring, D. (2017). Contributors to wellbeing and stress in parents of children with autism spectrum disorder. Research in Autism Spectrum Disorders, 37, 61-72. https:// doi.org/10.1016/j.rasd.2017.01.007

Coyne, L. W., McHugh, L., \& Martinez, E. R. (2011). Acceptance and commitment therapy (ACT): Advances and applications with children, adolescents, and families. Child \& Adolescent Psychiatric
Clinics of North America, 20(2), 379-399. https://doi.org/10. 1016/j.chc.2011.01.010

Dickinson, D., Wilkie, P., \& Harris, M. (1999). Taking medicines: Concordance is not compliance. BMJ, 319(7212), 787. https:// doi.org/10.1136/bmj.319.7212.787

Edwards, G. S., Zlomke, K. R., \& Greathouse, A. D. (2019). RUBI parent training as a group intervention for children with autism: A community pilot study. Research in Autism Spectrum Disorders, 66, 1-10. https://doi.org/10.1016/j.rasd.2019.101409

Fenning, R. M., \& Butter, E. M. (2019). Promoting parent engagement in parent training for children with autism spectrum disorder. In C. R. Johnson, E. M. Butter, \& L. Scahill (Eds.), Parent training for autism spectrum: Improving the quality of life for children and their families (pp. 61-84). American Psychological Association. https://doi.org/10.1037/0000111-004

Ferguson, J., Craig, E. A., \& Dounavi, K. (2019). Telehealth as a model for providing behavior analytic interventions to individuals with autism spectrum disorder: A systematic review. Journal of Autism \& Developmental Disorders, 49, 582-616. https://doi.org/10. 1007/s10803-018-3724-5

Fodstad, J. C., Kirsch, A., Faidley, M., \& Bauer, N. (2018). Demonstration of parent training to address early self-injury in young children with delays. Journal of Autism \& Developmental Disorders, 48(11), 3846-3857. https://doi.org/10.1007/s10803-018-3651-5

Fung, K., Lake, J., Steel, L., Bryce, K., \& Lunsky, Y. (2018). ACT processes in group intervention for mothers of children with autism spectrum disorder. Journal of Autism \& Developmental Disorders, 48(8), 2740-2747. https://doi.org/10.1007/s10803-018-3525-x

Garcia, Y., Keller-Collins, A., Andrews, M., Kurumiya, Y., Imlay, K., Umphrey, B., \& Foster, E. (2021). Systematic review of acceptance and commitment therapy in individuals with neurodevelopmental disorders, caregivers, and staff. Behavior Modification. Advance online publication. https://doi.org/10.1177/01454455211027301

Gould, E. R., Tarbox, J., \& Coyne, L. (2018). Evaluating the effects of acceptance and commitment training on the overt behavior of parents of children with autism. Journal of Contextual Behavioral Science, 7, 81-88. https://doi.org/10.1016/j.jcbs.2017.06.003

Hahs, A. D., Dixon, M. R., \& Paliliunas, D. (2019). Randomized controlled trial of a brief acceptance and commitment training for parents of individuals diagnosed with autism spectrum disorders. Journal of Contextual Behavioral Science, 12, 154-159. https:// doi.org/10.1016/j.jcbs.2018.03.002

Han, A., Yuen, H. K., Lee, H. Y., \& Zhou, X. (2020). Effects of acceptance and commitment therapy on process measures of family caregivers: A systematic review and meta-analysis. Journal of Contextual Behavioral Science, 18, 201-213. https://doi.org/10. 1016/j.jcbs.2020.10.004

Han, A., Yuen, H. K., \& Jenkins, J. (2021). Acceptance and commitment therapy for family caregivers: A systematic review and metaanalysis. Journal of Health Psychology, 26(1), 82-102. https://doi. org/10.1177/1359105320941217

Hanley, G. P. (2009). Open-ended functional assessment interview. https://practicalfunctionalassessment.files.wordpress.com/2015/ 06/open-ended-functional-assessment-interview.pdf

Hanley, G. P., Jin, C. S., Vanselow, N. R., \& Hanratty, L. A. (2014). Producing meaningful improvements in problem behavior of children with autism via synthesized analyses and treatments. Journal of Applied Behavior Analysis, 47(1), 16-36. https://doi.org/10. 1002/jaba.106

Hock, R., Kinsman, A., \& Ortaglia, A. (2015). Examining treatment adherence among parents of children with autism spectrum disorder. Disability \& Health Journal, 8(3), 407-413. https://doi.org/ 10.1016/j.dhjo.2014.10.005

Hofmann, S. G., \& Hayes, S. C. (2019). The future of intervention science: Process-based therapy. Clinical Psychological Science, 7(1), 37-50. https://doi.org/10.1177/2167702618772296 
Joekar, S., Farid, A. A. A., Birashk, B., Gharraee, B., \& Mohammadian, M. (2016). Effectiveness of acceptance and commitment therapy in the support of parents of children with high-functioning autism. International Journal of Humanities \& Cultural Studies, 2(4), 2763-2772.

Jones, E. A., Fiani, T., Stewart, J. L., Sheikh, R., Neil, N., \& Fienup, D. M. (2019). When one sibling has autism: Adjustment and sibling relationship. Journal of Child \& Family Studies, 28(5), 1272-1282. https://doi.org/10.1007/s10826-019-01374-z

Lecavalier, L., Smith, T., Johnson, C., Bearss, K., Swiezy, N., Aman, M. G., Sukhodolsky, D. G., Deng, Y., Dziura, J., \& Scahill, L. (2017). Moderators of parent training for disruptive behaviors in young children with autism spectrum disorder. Journal of Abnormal Child Psychology, 45(6), 1235-1245. https://doi.org/10.1007/ s10802-016-0233-x

Ledford, J. R., Barton, E. E., Severini, K. E., \& Zimmerman, K. N. (2019). A primer on single-case research designs: Contemporary use and analysis. American Journal on Intellectual \& Developmental Disabilities, 124(1), 35-56. https://doi.org/10.1352/19447558-124.1.35

Lee, E. H. (2012). Review of the psychometric evidence of the perceived stress scale. Asian Nursing Research, 6, 121-127. https:// doi.org/10.1016/j.anr.2012.08.004

Leijten, P., Melendez-Torres, G. J., \& Gardner, F. (2021). Research review: The most effective parenting program content for disruptive child behavior-a network meta-analysis. Journal of Child Psychology \& Psychiatry. Advance online publication. https:// doi.org/10.1111/jcpp.13483

Lerman, D. C., O’Brien, M. J., Neely, L., Call, N. A., Tsami, L., Schieltz, K. M., Berg, W. K., Graber, J., Huang, P., Kopelman, T., \& Cooper-Brown, L. J. (2020). Remote coaching of caregivers via telehealth: Challenges and potential solutions. Journal of Behavioral Education, 29, 195-221. https://doi.org/10.1007/ s10864-020-09378-2

Lunsky, Y., Fung, K., Lake, J., Steel, L., \& Bryce, K. (2018). Evaluation of acceptance and commitment therapy (ACT) for mothers of children and youth with autism spectrum disorders. Mindfulness, 9(4), 1110-1116. https://doi.org/10.1007/ s12671-017-0846-3

MacNaughton, K. L., \& Rodriguez, J. R. (2001). Predicting adherence to recommendations by parents of clinic-referred children. Journal of Counseling \& Clinical Psychology, 60, 262-270. https:// doi.org/10.1037/0022-006X.69.2.262

Matson, J. L., \& Rivet, T. T. (2008). Characteristics of challenging behaviors in adults with autistic disorder, PDD-NOS, and intellectual disability. Journal of Intellectual \& Developmental Disability, 33(4), 323-329. https://doi.org/10.1080/13668250802492600

Matson, J. L., Hess, J. A., \& Mahan, S. (2013). Moderating effects of challenging behaviors and communication deficits on social skills in children diagnosed with an autism spectrum disorder. Research in Autism Spectrum Disorders, 7(1), 23-28. https://doi. org/10.1016/j.rasd.2012.07.002

McStay, R. L., Trembath, D., \& Dissanayake, C. (2014). Stress and family quality of life in parents of children with autism spectrum disorder: Parent gender and the double ABCX model. Journal of Autism \& Developmental Disorders, 44(12), 3101-3118. https:// doi.org/10.1007/s10803-014-2178-7

Nock, M. K., \& Kazdin, A. E. (2001). Parent expectancies for child therapy: Assessment and relation to participation in treatment. Journal of Child \& Family Studies, 10, 155-180. https://doi.org/ 10.1023/A:1016699424731

Ong, C. W., Lee, E. B., Levin, M. E., \& Twohig, M. P. (2019). A review of AAQ variants and other context-specific measures of psychological flexibility. Journal of Contextual Behavioral Science, 12, 329-346. https://doi.org/10.1016/j.jcbs.2019.02.007
Pennefather, J., Hieneman, M., Raulston, T. J., \& Caraway, N. (2018). Evaluation of an online training program to improve family routines, parental well-being, and the behavior of children with autism. Research in Autism Spectrum Disorders, 54, 21-26. https://doi.org/10.1016/j.rasd.2018.06.006

Postorino, V., Sharp, W. G., McCracken, C. E., Bearss, K., Burrell, T. L., Evans, A. N., \& Scahill, L. (2017). A systematic review and meta-analysis of parent training for disruptive behavior in children with autism spectrum disorder. Clinical Child \& Family Psychology Review, 20, 391-402. https://doi.org/10.1007/ s10567-017-0237-2

Raulston, T. J., Hieneman, M., Caraway, N., Pennefather, J., \& Bhana, N. (2019). Enablers of behavioral parent training for families of children with autism spectrum disorder. Journal of Child \& Family Studies, 28, 693-703. https://doi.org/10.1007/ s10826-018-1295-x

Rayner, M., Dimovski, A., Muscara, F., Yamada, J., Burke, K., McCarthy, M., Hearps, S. J. C., Anderson, V. A., Coe, A., Hayes, L., Walser, R., \& Nicholson, J. M. (2016). Participating from the comfort of your living room: Feasibility of a group videoconferencing intervention to reduce distress in parents of children with a serious illness or injury. Child \& Family Behavior Therapy, 38(3), 209-224. https://doi.org/10.1080/07317107.2016.1203145

Rovane, A. K., Hock, R. M., \& January, S. A. A. (2020). Adherence to behavioral treatments and parent stress in families of children with ASD. Research in Autism Spectrum Disorders, 77, article 101609. https://doi.org/10.1016/j.rasd.2020.101609

Sairanen, E., Lappalainen, R., Lappalainen, P., Kaipainen, K., Carlstedt, F., Anclair, M., \& Hiltunen, A. (2019). Effectiveness of a web-based acceptance and commitment therapy intervention for wellbeing of parents whose children have chronic conditions: A randomized controlled trial. Journal of Contextual Behavioral Science, 13, 94-102. https://doi.org/10.1016/j.jcbs.2019.07.004

Scahill, L., Bearss, K., Lecavalier, L., Smith, T., Swiezy, N., Aman, M., Sukhodolsky, D. G., McCracken, C., Minshawi, N., Turner, K., Levato, L., Saulnier, C., Dziura, J., \& Johnson, C. (2016). Effect of parent training on adaptive behavior in children with autism spectrum disorder and disruptive behavior: Results of a randomized trial. Journal of American Academy of Child \& Adolescent Psychiatry, 55(7), 602-609. https://doi.org/10.1016/j.jaac. 2016.05.001

Sikora, D., Moran, E., Orlich, F., Hall, T. A., Kovacs, E. A., Delahaye, J., Clemons, T. E., \& Kuhlthau, K. (2013). The relationship between family functioning and behavior problems in children with autism spectrum disorders. Research in Autism Spectrum Disorders, 7, 307-315. https://doi.org/10.1016/j.rasd.2012.09.006

Snowden, A., Martin, C., Mathers, B., \& Donnell, A. (2014). Concordance: A concept analysis. Journal of Advanced Nursing, 70(1), 46-59. https://doi.org/10.1111/jan.12147

Stocco, C. S., \& Thompson, R. H. (2015). Contingency analysis of caregiver behavior: Implications for parent training and future directions. Journal of Applied Behavior Analysis, 48(2), 417-435. https://doi.org/10.1002/jaba.206

Strauss, K., Vicari, S., Valeri, G., \& D-Elia, L., Arima, S., \& Fava, L. (2012). Parent inclusion in early intensive behavioral intervention: The influence of parental stress, parent treatment fidelity and parent-mediated generalization of behavior targets on child outcomes. Research in Developmental Disabilities, 33(2), 688-703. https://doi.org/10.1016/j.ridd.2011.11.008

Tarver, J., Palmer, M., Webb, S., Scott, S., Slonims, V., Simonoff, E., \& Charman, T. (2019). Child and parent outcomes following parent interventions for child emotional and behavioral problems in autism spectrum disorders: A systematic review and meta-analysis. Autism, 23(7), 1630-1644. https://doi.org/10.1177/13623 61319830042 
Taylor, J. M. (2015). Psychometric analysis of the ten-item perceived stress scale. Psychological Assessment, 27, 90-101. https://doi. org/10.1037/a0038100

Tomlinson, S. R. L., Gore, N., \& McGill, P. (2018). Training individuals to implement applied behavior analytic procedures via telehealth: A systematic review of the literature. Journal of Behavioral Education, 27, 172-222. https://doi.org/10.1007/ s10864-018-9292-0

Tsami, L., Lerman, D., \& Toper-Korkmaz, O. (2019). Effectiveness and acceptability of parent training via telehealth among families around the world. Journal of Applied Behavior Analysis, 52(4), 1113-1129. https://doi.org/10.1002/jaba.645

Unholz-Bowden, E., McComas, J. J., McMaster, K. L., Girtler, S. N., Kolb, R. L., \& Shipchandler, A. (2020). Caregiver training via telehealth on behavioral procedures: A systematic review. Journal of Behavioral Education, 29(2), 246-281. https://doi.org/10.1007/ s10864-020-09381-7

Wainer, A., \& Ingersoll, B. (2014). Increasing access to an ASD imitation intervention via a telehealth parent training program. Journal of Autism \& Developmental Disorders, 45(12), 3877-3890. https://doi.org/10.1007/s10803-014-2186-7

Whittingham, K. (2015). Connect and shape: A parenting meta-strategy. Journal of Contextual Behavioral Science, 4(2), 103-106. https://doi.org/10.1016/j.jcbs.2015.03.002

Whittingham, K., \& Coyne, L. W. (2019). Acceptance and commitment therapy: The clinician's guide for supporting parents. Academic Press.

Whittingham, K., Sheffield, J., \& Sofronoff, K. (2010). Stress management for parents: Acceptance and commitment therapy. [Unpublished manuscript]. School of Psychology, University of Queensland.
Whittingham, K., Sanders, M., \& R., McKinlay, L., \& Boyd, R. N. (2014). Interventions to reduce behavioral problems in children with cerebral palsy: An RCT. Pediatrics, 133(5), e1249-e1257. https://doi.org/10.1542/peds.2013-3620

Whittingham, K., Sanders, M. R., McKinlay, L., \& Boyd, R. N. (2016). Parenting intervention combined with acceptance and commitment therapy: A trial with families of children with cerebral palsy. Journal of Pediatric Psychology, 41(5), 531-542. https://doi.org/ 10.1093/jpepsy/jsv118

Wong, C. C., Mak, W. W., \& Liao, K. Y. H. (2016). Self-compassion: A potential buffer against affiliate stigma experienced by parents of children with autism spectrum disorders. Mindfulness, 7(6), 1385-1395. https://doi.org/10.1007/s12671-016-0580-2

Yi, Z., \& Dixon, M. R. (2021). Developing and enhancing adherence to a telehealth ABA parent training curriculum for caregivers of children with autism. Behavior Analysis in Practice, 14(1), 58-74. https://doi.org/10.1007/s40617-020-00464-5

Zaidman-Zait, A., Mirenda, P., Duku, E., Szatmari, P., Georgiades, S., Volden, J., Zwaigenbaum, L., Vaillancourt, T., Bryson, S., Smith, I., Fombonne, E., Roberts, W., Waddell, C., \& Thompson, A. (2014). Examination of bidirectional relationships between parent stress and two type of problem behavior in children with autism spectrum disorder. Journal of Autism \& Developmental Disorders, 44(8), 1908-1917. https://doi.org/10.1007/s10803-014-2064-3

Publisher's Note Springer Nature remains neutral with regard to jurisdictional claims in published maps and institutional affiliations. 